\title{
The Feasibility of Air Classification of Dusts from the Iron and Steel Industry
}

\author{
Christof Lanzerstorfer ${ }^{1}$, Albert Angerbauer ${ }^{1}$, Michael Gaßlbauer ${ }^{1}$, Robert Neuhold ${ }^{2}$ \\ ${ }^{1}$ Process Engineering and Production Institute/University of Applied Sciences Upper Austria \\ Stelzhamerstraße 23, Wels, Austria \\ c.lanzerstorfer@fh-wels.at \\ ${ }^{2}$ Primetal Technologies Austria GmbH \\ Turmstraße 4, 4031 Linz, Austria \\ robert.neuhold@primetals.com
}

\begin{abstract}
In this paper, the feasibility of air classification of dusts from iron and steel production for improved recycling is investigated. By air classification a dust can be separated into a coarse fraction and a fine fraction. According to literature data some components which are usually unwanted in recycled material like alkali chlorides and the heavy metals $\mathrm{Zn}$ and $\mathrm{Pb}$ are enriched in the fine dust fraction. Therefore, air classification of dust before recycling would allow recycling of an increased amount of dust and reduce landfill. However, the benefits have to be measured against the cost of air classification. In order to be able to study the feasibility of such treatment the investment costs and the operating costs of a classification facility were calculated for three different dust treatment capacities. The results show that the three main factors affecting the feasibility of such a treatment are the capacity of the unit, the cost of landfill of the respective dust and the fraction of dust which can be recycled after the treatment. A cost curve per ton of processed dust is presented and shown for annual capacities of 2.370, 7.000 and $23.000 \mathrm{t}$. For the higher capacities it is shown that good feasibility is probable even if rather low landfill costs are assumed.
\end{abstract}

Keywords: Air classification, dust recycling, treatment cost, landfill

\section{Introduction}

The residue from dry air pollution control processes for off-gas de-dusting in the iron and steel industry is a finegrained material which either has to be recycled in some way or disposed of in landfill sites. The dusts separated from the off-gas of the blast furnace (BF), the basic oxygen furnace (BOF) and the sinter plant are rich in Fe and, therefore very often recycled inside the steel mill. Limitations for recycling usually arise from high content of $\mathrm{Zn}$ and $\mathrm{Pb}$ in the dusts or in the case of sinter plant dust from an increased content of alkali chlorides $(\mathrm{KCl}, \mathrm{NaCl})$. In several studies it has been shown that these unwanted components are especially enriched in the finest fractions of the dusts (BF top-gas dust [1-3], BF casthouse dust [4], BOF secondary dust [5], sinter plant dust [6,7]). Therefore, air classification of these dusts could be a feasible process to reduce such components in the bulk of the dust by separating off the finest fractions. The treatment of the sludge from wet off-gas cleaning of BFs by hydro-cyclones is a well-established process. In this application the fine fraction which is enriched in $\mathrm{Zn}$ is separated from the sludge. Air classification could be used in a similar way for the residues from dry off-gas de-dusting. However, the costs are expected to be higher for air classification compared to classification in hydro-cyclones because an air classifier is a much more complex and expensive machine compared to a hydro-cyclone.

In this study, the cost of air classification of dust was investigated for several treatment capacities of the air classification unit. The obtained costs for air classification resulting from the investment and the operating costs of the classification unit were compared with typical landfill costs for such dusts.

\section{Plant concept}

The chosen method for the evaluation was integration of an air classification plant (ACP) as a greenfield plant into an existing steel works [8]. The concept is that the dust is transported by truck to the ACP and then stored in a silo for 
processing. The resulting fine and coarse fraction are stored in separate silos. The coarse fraction is then recycled in the steel works. The fine fraction with the bulk of unwanted elements is either transported to landfill or recycled in some way outside the steel works. The basic flow diagram of the APC is shown in Figure 1. The process starts on the left with the pneumatic unloading of the input material into the storage silo by means of an onboard compressor. Then the material is transported mechanically into the classifier and the coarse portion is also transported in this way out of the machine. The size of the silos was set to about $100 \mathrm{~m}^{3}$, which comes from the idea that a minimum of two truckloads can be dumped. The filter for the fines is very important for cost calculation. Ventilation is placed at the end of the flow, so the plant is operated in under-pressure mode. The loading of the departing trucks is done by load bellows, as the truck is located directly under the respective silo.

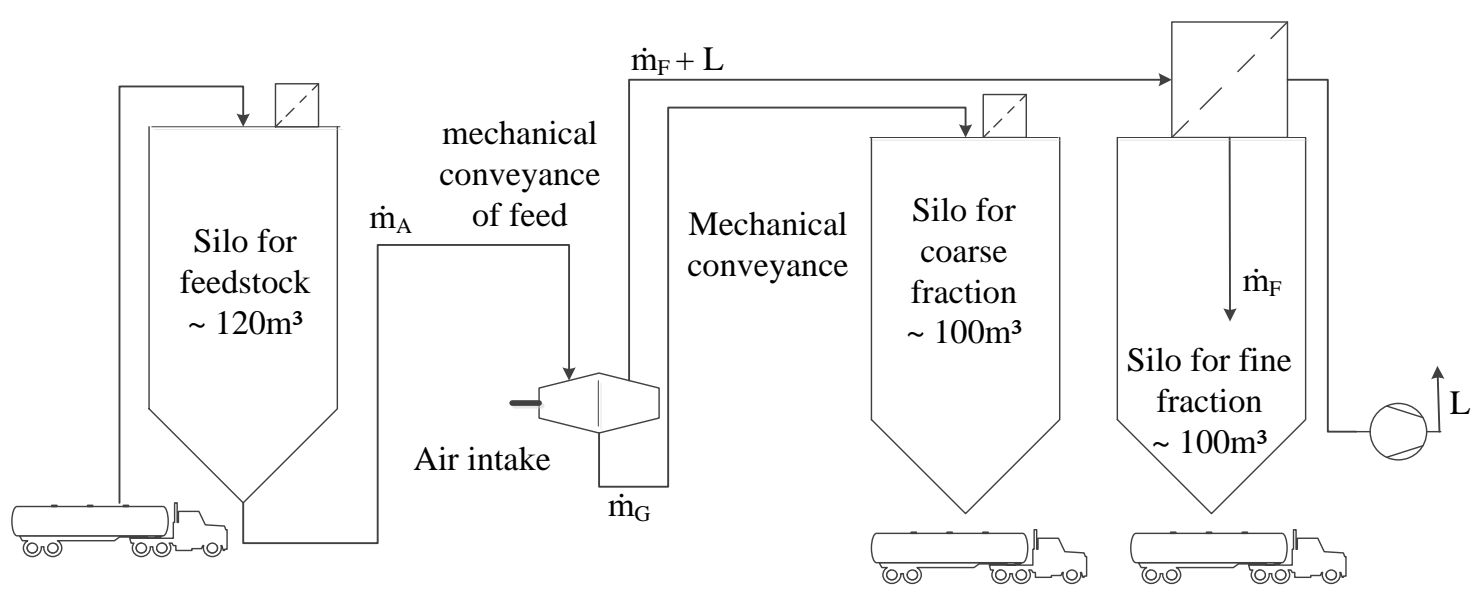

Fig. 1: Flow diagram of an ACP.

The core component of the plant is a dynamic air classifier, which is in industrial use in several variants. The fine granular material is fed to the classifier either pneumatically or by a mechanical conveyor. Additionally, air is fed to the classifier to disperse the dust. The classifier wheel is of adjustable speed and provides for dynamic acceleration of the dispersed particles when they enter the wheel. Coarse particles gain a higher impact and are moved towards the side walls, from where they fall by gravity to the coarse material outlet. The fine particles are transported with the air to the center of the classifier wheel and have to be separated from the air flow in a bag filter. By adjusting wheel speed and air flow, separation can be managed. Higher speed leads to a lower value of the cut size $\mathrm{x}_{\mathrm{T}}$, which is the particle size to end up in the coarse fraction or in the fine fraction with equal probability.

To obtain an investment as well as an operating cost curve, the plant concept has to be worked out for a number of material treatment capacities. To provide the cost calculation in a transparent and comprehensible manner, the investment for the main components was estimated on the basis of quotations. This required a plant concept on a basic engineering level, but the process design of the plant was not needed in detail.

The amount of dust which has to be air-classified and the required cut size of the classification depend on the application and the capacity of the steel works. An overview of the specific dust generation rates of the various process steps of steel works can be found in the BAT reference document [9]. However, the presented values vary within a wide range. Therefore, the design capacity for the ACP was defined by experience. Three capacities were selected $(300 \mathrm{~kg} / \mathrm{h}$, $1,000 \mathrm{~kg} / \mathrm{h}$ and $3,000 \mathrm{~kg} / \mathrm{h}$ ). Thus, the plant concept should be applicable to electrostatic precipitator dust from a sinter plant as well as to dusts from a BF (dust catcher, cast-house de-dusting and second stage dry top-gas cleaning) and from secondary de-dusting of a BOF.

The required cut size is expected to be in the range of $2-10 \mu \mathrm{m}$ [2-5,7]. However, this value can only be given in a range where actual trial runs have to be performed. Therefore, the concept of the ACP has to be highly adjustable as mentioned above, as separation size can be set by means of air supply and wheel speed. It is also possible to classify feeds from different processes and plants, as process control can set the production parameters accordingly for each lot. 
The bulk density of the dusts is an important parameter for the selection of the size of the silos. Typical ranges of the bulk density of dusts from sinter plants, BFs and BOFs are $500-1500 \mathrm{~kg} / \mathrm{m}^{3}$ and the values of the material density are in the range from $2500-4000 \mathrm{~kg} / \mathrm{m}^{3}[6,10-12]$.

Based on the flow diagram (Figure 1) the basic engineering for the ACPs was elaborated. The main process equipment of an ACP is the air classifier. An investigation of suppliers of suitable air classifiers showed that there are a number of capable companies. However, references in the steel industry are still rarely to be found. The main differences between air classifiers from different suppliers are in the type of feeding. Options are air or mechanical feed. The same applies for the transport of the coarse fraction. For the ACPs, air classifiers with mechanical conveying of the feed and the coarse material were selected. The size of the silos was selected to have a storage capacity for more than one silo truck even at the lowest bulk density.

Before the cost calculation was started, an overall layout of the site was worked out (Figure 2) for a proper estimate of site costs. If the ACP is located directly beside a road, a field of $600 \mathrm{~m}^{2}$ would suffice. The $50 \mathrm{~m}^{2}$ building with an eaveheight of about $5 \mathrm{~m}$ can be of a standard industrial prefabricated type, placed on a concrete basement. The storage silos of the coarse and fine material will be the tallest buildings with a height of about $18.5 \mathrm{~m}$ over ground level.

Table 1: Major aggregates of the ACPs.

\begin{tabular}{|l|c|c|c|}
\hline \multirow{2}{*}{ Equipment } & \multicolumn{3}{|c|}{$\mathrm{ACP}$} \\
\cline { 2 - 4 } & $300 \mathrm{~kg} / \mathrm{h}$ & $1,000 \mathrm{~kg} / \mathrm{h}$ & $3,000 \mathrm{~kg} / \mathrm{h}$ \\
\hline Air classifier with electric drive & $5 \mathrm{~kW}$ & $15 \mathrm{~kW}$ & $35 \mathrm{~kW}$ \\
\hline Dosing screw conveyor electric drive & $0.45 \mathrm{~kW}$ & $0.55 \mathrm{~kW}$ & $0.55 \mathrm{~kW}$ \\
\hline Vacuum pump & $7.5 \mathrm{~kW}$ & $30 \mathrm{~kW}$ & $55 \mathrm{~kW}$ \\
\hline Silo for feed dust (made of Al) & $120 \mathrm{~m}^{3}$ & $120 \mathrm{~m}^{3}$ & $120 \mathrm{~m}^{3}$ \\
\hline Silo for fine fraction (made of Al) & $100 \mathrm{~m}^{3}$ & $100 \mathrm{~m}^{3}$ & $100 \mathrm{~m}^{3}$ \\
\hline Silo for coarse fraction (made of Al) & $100 \mathrm{~m}^{3}$ & $100 \mathrm{~m}^{3}$ & $100 \mathrm{~m}^{3}$ \\
\hline Dust conveyor & $5.5 \mathrm{~kW}$ & $5.5 \mathrm{~kW}$ & $7.5 \mathrm{~kW}$ \\
\hline Cartridge dust filter for feed dust silo & $30 \mathrm{~m}^{2}$ & $30 \mathrm{~m}^{2}$ & $30 \mathrm{~m}^{2}$ \\
\hline Cartridge dust filter for coarse fraction silo & $3 \mathrm{~m}^{2}$ & $5 \mathrm{~m}^{2}$ & $8 \mathrm{~m}^{2}$ \\
\hline Dust filter for fine fraction & $\begin{array}{c}\text { incl. with } \\
\text { classifier }\end{array}$ & $\begin{array}{c}\text { incl. with } \\
\text { classifier }\end{array}$ & $\begin{array}{c}\text { incl. with } \\
\text { classifier }\end{array}$ \\
\hline Compressed air system with refrigeration dryer & $500 \mathrm{dm}^{3} / \mathrm{min}$ & $500 \mathrm{dm}^{3} / \mathrm{min}$ & $500 \mathrm{dm}^{3} / \mathrm{min}$ \\
\hline
\end{tabular}




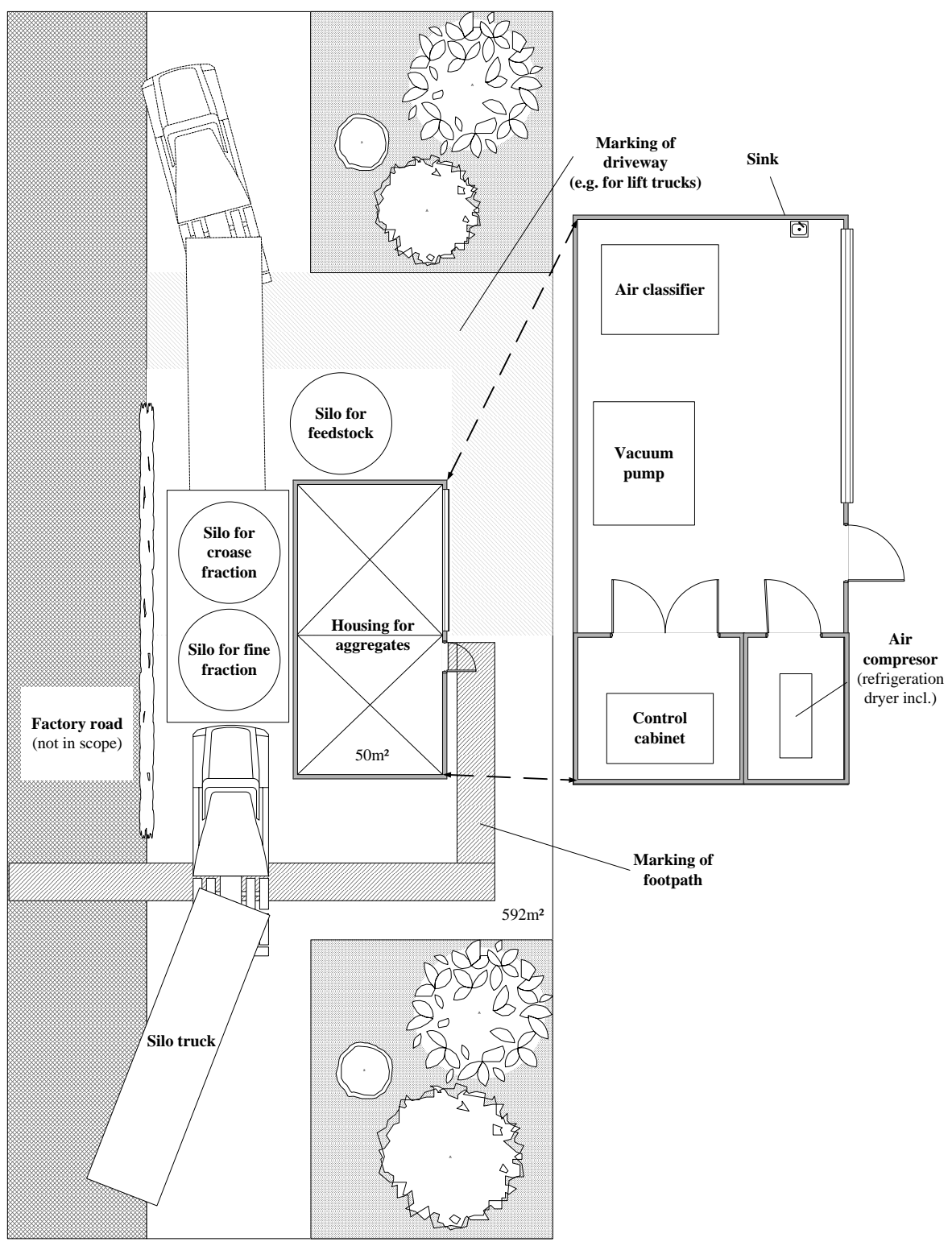

Fig. 2: Plant layout.

\section{Cost estimation}

For cost estimation a site location in Central Europe (Southern Germany, Austria) was assumed. The differences between the plant sizes results mainly from the differences in the air classifier and the conveyors (Table 1) but not significantly from costs for buildings and storage units. Furthermore, engineering costs do not depend on the plant size and an estimate of $650 \mathrm{~h}$ was taken into account.

The investment and operation costs of the ACPs are summarized in Table 2. In the calculation a payback period for the investment of 10 years was assumed, financing cost 5\% per year (interests, services). For the estimation of the personnel costs, it was assumed that the plant is handled in remote control mode, so personnel are shared with other facilities. As the operation will have no direct necessity of local interaction, a $25 \%$ share of one full-time resource was assumed to be sufficient to run the plant. The cost for unloading und loading was assigned to the transportation costs, which are excluded from this calculation. The unloading costs appear in today's plant management as well, as the dust has to be brought to landfill sites or other recycling facilities anyway.

The operation of the plant will be in three shifts with planned maintenance stops. Taking into account other reasons for stoppages such as shut-downs of the dust producing facilities, a net production time of about 7,900 h/a was assumed. This 
means that four shifts have to be filled and so personnel costs of one person have to be calculated in total for all ACP types. A value of roughly 57,000.- EUR per year was estimated for the chosen location based on local rates.

Table 2: Investment cost and operation cost of ACPs.

\begin{tabular}{|l|c|c|c|}
\hline \multirow{2}{*}{} & \multicolumn{3}{|c|}{ ACP } \\
\cline { 2 - 4 } & $300 \mathrm{~kg} / \mathrm{h}$ & $1,000 \mathrm{~kg} / \mathrm{h}$ & $3,000 \mathrm{~kg} / \mathrm{h}$ \\
\hline Annual plant capacity & $2,370 \mathrm{t} / \mathrm{a}$ & $7,900 \mathrm{t} / \mathrm{a}$ & $23,700 \mathrm{t} / \mathrm{a}$ \\
\hline Investment cost (greenfield, in EUR) & $780,000 .-$ & $850,000 .-$ & $1,050,000 .-$ \\
\hline Cost per year (in EUR) & $78,000 .-$ & $85,000 .-$ & $105,000 .-$ \\
\hline Depreciation & $4,000 .-$ & $4,000 .-$ & $5,000 .^{-}$ \\
\hline Financing (rounded) & $57,000 .-$ & $57,000 .-$ & $57,000 .-$ \\
\hline Personell & $25,000 .-$ & $58,000 .-$ & $104,000 .-$ \\
\hline Electric power & $9,000 .-$ & $9,000 .-$ & $9,000 .-$ \\
\hline Maintenance & $173,000 .-$ & $213,000 .-$ & $280,000 .-$ \\
\hline Total annual cost & &
\end{tabular}

The prediction of the energy cost is very much dependent on the place of operation. At the time a figure of 120 EUR/MWh seemed to be reasonable. The estimated electric power consumption of the small, medium and large ACP was $210 \mathrm{MWh}, 480 \mathrm{MWh}$ and $870 \mathrm{MWh}$, respectively. Maintenance was derived from quotations from specialized companies and a figure of 9,000.- EUR per year was found plausible, which depends little on the size of the plant.

The resulting specific costs for air classification were 73.0 EUR/t, 27.0 EUR/t, and 11.8 EUR/t in a small, medium and large ACP.

\section{Results and Discussion}

The operating efficiency of an ACP plant mainly depends on its benefits. There are two main ones. The first is the avoidance of landfill costs. Only the mass portion of fines would have to go to landfilled after air classification, the coarse fraction would be recycled. A second benefit would come from the bonus for the valuable raw material, especially Fe and also $\mathrm{C}$ in the case of BF dust, that goes with the recycled material. In the following, such bonuses were not further investigated, as this is a very specific issue of steel operations. It is clear that the calculation could also produce a negative bonus if the recycling causes additional operation costs. So the assumption is that the set point of $\mathrm{x}_{\mathrm{T}}$ is such that no negative influences to the process occur. The only source of revenue for the operating costs and the payback of the investment is the saving in landfill cost then.

Appropriate numbers for landfill costs of dust from steelworks is hard to find in literature. Steel works do not make public such cost rates and there is no appropriate parameter which can be taken from waste handling companies, as the amount of waste is much higher in this case usual e.g. in the construction business.

However, one source for this paper was the online service "Baupreislexikon.de" which is widely used in the construction business in Germany for price calculation [13]. It is clear that this service does not offer a value for filter dust from the steel industry but the aim was to find a figure below which landfill of such waste will not go. The section "metallic waste loaded with zinc" was chosen together with "dust-tight loading at filling site". The database computed costs of about 80.- EUR/t.

In a recent study the cost for landfill of untreated municipal waste incineration fly ash of 220.- EUR/t was used, whereas landfill of inert fly ash after leaching was said to be 36.- EUR/t [14]. In another study nearly ten years ago the cost for landfill of electric arc furnace dust of 125.- EUR/t was used, whereas landfill from processes with an inert mixture of dust of this kind together with cement were said to be 20.- EUR/t [15].

Another parameter which influences the profitability of an ACP significantly is the fraction of coarse material which can be utilized. This fraction depends on composition of dust and the specific circumstances at the steel works. Therefore, it is used as a variable parameter in the further discussion. 
From the calculated costs equation Eq. (1) was derived for the processing cost per tone $c_{p}$ in EUR at various feed values. In Eq. (1) $\mathrm{w}$ is the mass of dust which has to be air classified in $t / h$. The values obtained for the parameters $a, b$ and $\mathrm{n}$ were $24.5,2.5$ and -0.876 , respectively.

$$
c_{p}=a(w)^{n}+b
$$

Based on this it is possible to calculate the break-even point at different landfill cost rates $c_{l}$ in EUR per tonne and different fractions of fines $y_{f}$ which still have to be sent to landfill after classification. The condition for positive revenue from the investment is given by Eq. (2):

$$
c_{l} \geq c_{p}+y_{f} \cdot c_{l}
$$

The figure for the minimum landfill $\operatorname{cost} c_{l}^{*}$ above which the investment is feasible is concluded by Eq. (3):

$$
c_{l}^{*}=\frac{a(w)^{n}+b}{1-y_{f}}
$$

For the investigated case the results are plotted in Figure 3 to illustrate the effect of fines rate and plant capacity on the required minimum landfill rate for feasibility. The model can also be adapted for different local conditions.

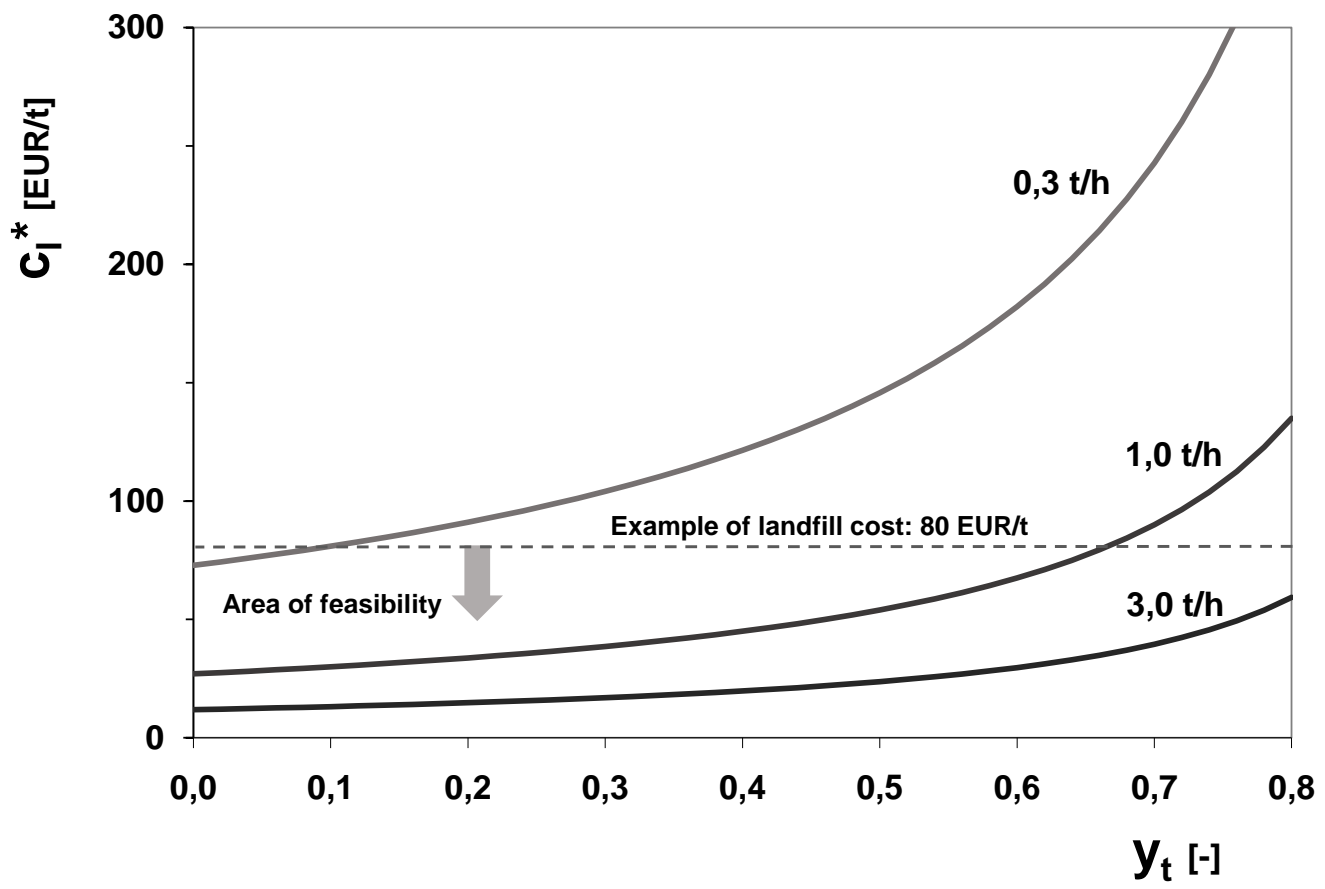

Fig. 3: Minimum landfill rates for feasibility at different fines rates and plant capacities.

\section{Conclusion}

As shown, there is a high probability that with use of air classifiers the amount of landfilled dust from sinter plants, $\mathrm{BFs}$ and BOFs can be substantially reduced. Even if moderate rates for landfill are taken into account, economic feasibility over ten years was demonstrated. It is clear that for most steel companies this issue is not a priority, however. One reason could be that additional recycling of raw material is required, another that available space for landfill is limited. 
Nevertheless, the idea and the proof of feasibility will become a more important issue in the discussion on good waste treatment when the first ACP plants become public as available technology for effective recycling of dust from steel plants.

\section{Acknowledgements}

Proofreading by P. Orgill is gratefully acknowledged. This work was funded by K1-MET. K1-MET is a member of COMET - Competence Centers for Excellent Technologies and is financially supported by the BMVIT (Federal Ministry for Transport, Innovation and Technology), BMWFJ (Federal Ministry of Economy, Family and Youth), the federal states of Upper Austria, Styria and Tyrol, SFG and Tiroler Zukunftsstiftung. COMET is managed by FFG (Austrian research promotion agency).

\section{References}

[1] T. Murai, A. Kometani, Y. Ono and T. Hashimoto, "Blast Furnace Gas Dry Cleaning System and Dry Removal System of Zing in Dry Dust," The Sumitomo Search, no. 32, pp. 1-7, 1986.

[2] C. Lanzerstorfer and M. Kröppl, "Air classification of blast furnace dust collected in a fabric filter for recycling to the sinter process," Resour. Conserv. Recy., vol. 86, no. 1, pp. 132-137, 2014.

[3] C. Lanzerstorfer, "Air classification of blast furnace dust catcher dust for zinc load reduction at the sinter plant," Int. J. Environ. Sci. Technol., vol. 13, no. 2, pp. 755-760, 2016.

[4] C. Lanzerstorfer, "Characterization of dust from blast furnace cast house de-dusting," Environ. Technol., DOI:10.1080/09593330.2016.1264487, 2016.

[5] C. Lanzerstorfer, "Air Classification of Dust from Steel Converter Secondary De-Dusting for Zinc Enrichment," Int. J. Chem. Molecular, Nuclear, Mater. Met. Eng., vol. 11, no. 1, pp. 65-72, 2017.

[6] C. Lanzerstorfer and D. Steiner, "Characterization of sintering dust collected in the various fields of an electrostatic precipitator," Environ.Technol., vol. 37, no. 12, pp. 1559-1567, 2016.

[7] C. Lanzerstorfer, "Application of air classification for improved recycling of sinter plant dust," Resour. Conserv. Recy., vol. 94, no. 1, pp. 66-71, 2015.

[8] M. Gaßlbauer, "Feasibility einer Anlage zur Korngrößenklassierung von Reststoffen aus der Entstaubung von Stahlwerken," Thesis, University of Applied Siences Upper Austie, 2016.

[9] R. Remus, M. A. Aguado-Monsonet, S. Roudier and L. D. Sancho, "Best Available Techniques (BAT) Reference Document for Iron and Steel Production," Industrial Emissions Directive 2010/75/EU, Integrated Pollution Prevention and Control, Luxembourg: Publications Office of the European Union, 2013.

[10] C. Lanzerstorfer, "Mechanical properties of dust collected from blast furnace dust catchers and cast house de-dusting filters," Particul. Sci. .Technol., vol. 34, no. 3, pp. 366-372, 2016.

[11] C. Lanzerstorfer, "Mechanical properties of dust collected by dust separators in iron ore sinter plants," Environ. Technol., vol. 36, no. 24, pp. 3186-3193, 2015.

[12] C. Lanzerstorfer, "Silo storage of dusts from dry off-gas cleaning: consideration of the stress dependence of the bulk density," Adv. Powder Technol., vol. 28, no. 1, pp. 115-121, 2017.

[13] Blödorn pr (PR-Agency, Karlsruhe, DE), „baupreislexikon.de: 45.000 eingetragene Anwender”, 2010, [Online]. Available: http://www.openpr.de/news/460383/baupreislexikon-de-45-000-eingetragene-Anwender.html

[14] J. Fellner, J. Lederer, A. Purgar, A. Winterstetter, H. Rechberger, F. Winter, D. Laner, "Evaluation of resource recovery from waste incineration residues - The case of zinc," Waste Manage., vol. 37, no. 1, pp. 95-103, 2015.

[15] G. Salihoglu, V. Pinarli, "Steel foundry electric arc furnace dust management: Stabilization by using lime and Portland cement," J. Hazard. Mater., vol. 153, no. 3, pp. 1110-1116, 2008. 